\title{
Using Machine Learning in Business Process Re-Engineering
}

\author{
Younis Al-Anqoudi *(D), Abdullah Al-Hamdani, Mohamed Al-Badawi (D) and Rachid Hedjam \\ Department of Computer Science, Sultan Qaboos University, P.O. Box 36, Muscat 123, Oman; \\ abd@squ.edu.om (A.A.-H.); mbadawi@squ.edu.om (M.A.-B.); rachid.hedjam@squ.edu.om (R.H.) \\ * Correspondence: s22781@student.squ.edu.om
}

Citation: Al-Anqoudi, Y.;

Al-Hamdani, A.; Al-Badawi, M.; Hedjam, R. Using Machine Learning in Business Process Re-Engineering. Big Data Cogn. Comput. 2021, 5, 61. https://doi.org/10.3390/bdcc5040061

Academic Editor: Carson K. Leung

Received: 19 September 2021

Accepted: 29 October 2021

Published: 2 November 2021

Publisher's Note: MDPI stays neutral with regard to jurisdictional claims in published maps and institutional affiliations.

Copyright: (C) 2021 by the authors. Licensee MDPI, Basel, Switzerland. This article is an open access article distributed under the terms and conditions of the Creative Commons Attribution (CC BY) license (https:/ / creativecommons.org/licenses/by/ $4.0 /)$.

\begin{abstract}
A business process re-engineering value in improving the business process is undoubted. Nevertheless, it is incredibly complex, time-consuming and costly. This study aims to review available literature in the use of machine learning for business process re-engineering. The review investigates available literature in business process re-engineering frameworks, methodologies, tools, techniques, and machine-learning applications in automating business process re-engineering. The study covers 200+ research papers published between 2015 and 2020 in reputable scientific publication platforms: Scopus, Emerald, Science Direct, IEEE, and British Library. The results indicate that business process re-engineering is a well-established field with scientifically solid frameworks, methodologies, tools, and techniques, which support decision making by generating and analysing relevant data. The study indicates a wealth of data generated, analysed and utilised throughout business process re-engineering projects, thus making it a potential greenfield for innovative machinelearning applications aiming to reduce implementation costs and manage complexity by exploiting the data's hiding patterns. This suggests that there were attempts towards applying machine learning in business process management and improvement in general. They address process discovery, process behaviour prediction, process improvement, and process optimisation. The review suggests that expanding the applications to business process re-engineering is promising. The study proposed a machine-learning model for automating business process re-engineering, inspired by the Lean Six Sigma principles of eliminating waste and variance in the business process.
\end{abstract}

Keywords: business process re-engineering; data mining; machine learning

\section{Introduction}

An organisation, an enterprise, or a company comprises a set of organised and connected business processes and activities arranged in a sequence, requiring efficient and effective process management to achieve strategic targets, objectives, and goals [1].

In that sense, business processes are a systematic approach for managing work and achieving targets [2]. Furthermore, because of the dynamic nature of the business, organisations tend to evolve through growth, transformation, or expand the organisation marketplace [3]. This impacts the business processes; therefore, it has to be reflected in the processes to realign with the needs of the business. Furthermore, since the first industrial revolution when Henry Ford introduced the assembly production line, business processes have played a pivotal role in managing and enhancing productivity [4]. Therefore, process science emerged theoretically and practically innovated many tools and techniques, such as business process re-engineering, as a powerful technique to improve process productivity [5].

Furthermore, as a dynamic component, a business process is affected by events occurring in the external world and other internal processes in the same organisation [6]. Consequently, as business process management evolved and became a commodity for business management, it evolved from the initial business process re-engineering in the 1980s to a well-established management approach [7]. Additionally, business processes management strategies improved monitoring and controlled productivity, profitability, 
service delivery levels, and other business objectives [8]. Subsequently, when the business grows, transforms, or expands, business process efficiency gets affected. Similarly, process productivity gets impacted, especially in highly competitive industries [3], which poses the need to redesign the processes to cope with the business evolvements [9].

Furthermore, due to process automation and digital transformation, lots of manual work transformed into digital platforms. Enterprise Resource Planning (ERPs) is a good example [10]. That is because it laid the foundation for automating the process in digital platforms, also known as workflow management systems, which accelerated and impacted productivity, efficiency, and effectiveness [11].

Automation equipped the organisation with a wealth of data and detailed records [12]. The rapid advancements in information technology, automation, and digital transformation raised the bar to challenge the purpose of the process itself before looking at improving its performance or re-engineering it [13].

Process improvement as a concept was introduced initially in 1991 by James Harrington, who applied it to situations where incremental changes are made to process design to meet new requirements or increase an existing business process efficiency [9]. Business process improvement employs various strategies and approaches, such as business process re-engineering [5], which Michael Hammer introduced in the 1990s. The business process re-engineering entails redesigning the process from scratch — rethinking and radically redesigning the business process achieves dramatic improvements [9]. Any change in the activities and the business process flow is re-engineering [3,14]. Re-engineering a business process will sometimes transform every aspect of an organisation, including organisation structures, values, and reward systems [15], maximising the impact of the change on the organisation culture.

Additionally to all the above, because of the globally recognised value of business process re-engineering and its positive impact on the financial status and operational productivity [1], business process re-engineering became part of the top continuous improvement strategies. Therefore, demand for business process re-engineering expertise and techniques increased tremendously; consequently, associated costs jumped exponentially.

A thought might occur: if business process re-engineering projects are expensive and complex, why do organisations insist on going that route? This is because the real challenge is the need for evolution and continuous improvement. If the process did not evolve, there would be a risk of losing market space and competitive advantages. For example, Nokia has been leading the mobile phones production industry for years, until they could not cope with the accelerated progress in the global mobile phones market. As a result, Nokia was out of the market after being the leading organisation.

The above sequence of advancements from the founding of the business process to the need to continue improving and re-engineering it, motivated the questioning of the existence of any automated artificial intelligence ways to reduce the cost and improve the outcomes of business process re-engineering projects.

Therefore, considering the above-listed challenges, there was a need to investigate alternative, unconventional ways to deliver better outputs with reduced cost and time.

As there were an enormous amount of digital data that became available, the next step was to utilise data mining and process mining [14] to analyse data to solve problems and develop insights [16]. Nonetheless, data science focuses on data-related subjects, such as data quality, without considering business process-related issues, such as improving process performance. Therefore, process mining emerged to reduce the gap between data science and process science [17].

Furthermore, artificial intelligence and machine learning progressively show the value of utilising available data. Its value enables learning knowledge from data to uncover hidden patterns and innovate new solutions [18] to complex real-life problems.

The hypothesis is that because the process data are available, there is an opportunity to utilise that data through machine learning to automate the business process re-engineering. However, the data might not be available immediately and may require formulation. 
Therefore, there is a need to consider making new data sources and to qualify them as input features for a machine-learning algorithm.

Consequently, as highlighted above, a wealth of data are generated, analysed, and utilised because of the digitalisation and automation of business processes, which is motivated by the fact that data mining and machine learning is an option. Therefore, this study aims to bridge data mining and machine learning with business process reengineering as a possible solution.

Knowing the capabilities of machine learning influenced this study's central question: To what degree has research contributed to shaping machine-learning utilisation in automating business process re-engineering?

This question has three investigation areas:

1. Knowing the fundamentals: What available frameworks, methodologies, tools, and techniques are used in re-engineering a business process?

2. Investigating related work: Were there any attempts to automate the business process re-engineering using machine learning?

3. Laying out the foundation: what data attributes and datasets are required for a machine-learning model to train and test in order to automate business process re-engineering?

The paper is structured as follows: in Section 2, there is a literature review on business process re-engineering, its manual implementation frameworks, methodologies and tools, the use of machine learning and data mining, and attempts to automate it. The findings in Section 3 highlight the main findings. The discussion in Section 4 discusses the proposed model to automate the business process re-engineering and the conclusion in Section 5.

\section{Literature Review}

Business process re-engineering became one of the most popular change-management approaches because it promotes doing things effectively for better overall quality. However, it is estimated that around $70 \%$ of business process re-engineering implementations have failed due to a lack of proper framework or methodology [15].

Multiple frameworks and methodologies are available for the business process reengineering management. Most frameworks and methodologies usually look at the process change in three main phases: (1) the process status as it is (as-is) highlighting the challenges and the need to change, (2) the process of redesigning mutable alternative designs of the process, and (3) the impact on the running instances of the process. Below are selected examples of frameworks and methodologies.

This review looks at available business process re-engineering frameworks, methodologies, tools, and techniques to investigate the related data generated, analysed, and utilised throughout the process. Finally, the study reviews related work that utilises machine learning for business process management in general and business process re-engineering in specific.

\subsection{Frameworks}

A framework is a structured way of working in order to manage progress towards achieving targets and objectives [19]. Business process re-engineering as a well-established process redesign model has many frameworks. From available frameworks, in this review, the researchers looked at the Mendling framework, Motwani framework, Al-Mashari and Zairi framework, Robert's framework, Lowenthal's framework, and Cross framework. In addition, TOGAF (The Open Group Architecture Framework), a framework from the information technology practices, was considered and mapped to the principles of business process re-engineering frameworks. More details about these frameworks are below:

- Mendling framework: distinguishes the re-engineering process into three levels: process relations, process modelling, and process execution and performance [20]. This framework outlines the tasks at each level, segregates the strategic tasks of the implementation process, and illustrates the difference between modelling a business 
process and using it in daily operations. The framework provides techniques that enable the organisation to identify and model business processes with a prioritisation mechanism. At the process model management level, and because of the impeded continuous improvement concept, new versions of the same business process get released to production between now and then, which requires a reliable way to distinguish running cases based on the process model version. This framework proposes a continuous process improvement in a cycle of tasks that enables the process owner to have visibility on the process performance at all the time with prompt identification for any need for improvement.

- Motwani framework: unlike Mendling, it does not consider having a repository for all business processes as a knowledge pool. Instead, it looks individually at each change requirement. The Motwani framework has six phases:

1. Understanding the scope of work.

2. Initiating the project with agreed upon and measurable objectives.

3. Programming requires baseline and benchmarking.

4. Transforming the process from the old version to the new version.

5. Implementing the change.

6. Evaluating success mapped to the objectives.

According to Motwani et al., a clear vision of the ideal process is required, which emerges as the final redesign goal [21].

- Al-Mashari and Zairi framework is a holistic framework, as they describe it, for business process re-engineering implementation [15]. This framework begins by looking at the internal and external change drivers, then benchmarking to determine the scope of the change, the degree of the change, and the change radicalness. The implementation phase has categorised the tools and techniques into enabling, facilitating, integrating, and implementating the tools and techniques. However, it has a critical gap in evaluating the outcome, as it is not adequately covered. The philosophy of this framework sums up the revolutionary magnitude of change based on breakthrough, one-time, or episodic approaches [22].

- Robert's framework took the steps very carefully where situational assessments plugged in nearly all stages, forming a continuous improvement process that starts again when it ends. The cycle begins with assessing and analysing the current opportunities and capabilities to propose a redesign, which triggers iterations of risk assessment and impact on the organisation output, a transition plan is made, and pilot testing conducted. This will give either the confidence to go ahead with the new process design and amend improvements, or corrections will be made to the proposed process with iterations to improve it before implementing the change in the production environment. When all tests pass the requirements, the framework recommends implementing the required modifications before implementing and transitioning to the new process. As a final stage, Robert's framework closely tracks the recent process performance and reinitiates the cycle again for further improvement. However, using practical change management tools to manage the resistance to change is a factor for failure or success of the business process re-engineering projects [23].

- Lowenthal's framework is a simple and basic framework of four phases [15], with a high-level sequence of steps:

1. Preparing for the change.

2. Planning.

3. Redesigning the process.

4. Evaluating the change.

The simplicity in this framework does not give much attention to analysing the need for the process redesign or benchmarking in depth. After implementing the change, it does not explicitly cover phases, such as testing, training, organisation change, and process performance monitoring. In general, Lowenthal's framework will not work for massive 
and complicated process redesign projects that require more details and focus. Instead, it is more suitable for implementing small incremental changes.

- The Cross framework distinguishes the tasks into three main phases (Analysis, Design, and Implementation) with a detailed list of the activities in each stage. The analysis phase covers the requirements analysis part very well. It gives explicit attention and consideration to the consumer requirements and makes changes driven by the customer needs, which provides more value and relevancy to the customer. In addition, it impacts the assessment of changes and their success or failure. Baseline analyses and current process reviews are also used with the customer requirements to build a 3-dimensional view of the design specifications. In the design phase, Cross et al. introduced a list of design principles helping the redesign team qualify the design options at a high level of design. This produces a detailed re-engineered design for the process. The new design is then injected into cycles of testing involving clients, in order to get their feedback until it achieves a satisfactory level and consensus agreement on the new process. The new process will then be moved to the implementation phase to transform the business into the new process. However, the Cross et al. framework does not address the impact on process performance after the implementation. Similarly, it does not address the continuous improvement concept [15].

- TOGAF (The Open Group Architecture Framework) is a comprehensive framework widely used in industry to manage information technology architecture in complex environments with impeded continuous improvement concepts. However, the study did not find any relevant academic research implementation for business process redesign, optimisation, or improvement research. This might be because TOGAF is an information technology framework applied to improve information technology architecture and performance, which is an opportunity, as information technology empowers business processes. [24]

Part of the review compares between the frameworks above, as illustrated in Table 1. The purpose of the comparison is to confirm the areas that each framework covers throughout the process, as the comparison table maps the frameworks in the following areas: need analysis and scoping, alignment with business strategy, benchmarking, developing alternative processes designs and qualifying the best out of them, testing involving endusers, training and knowledge management, handling process performance, transition from the old version to the new version of the redesigned processes, evaluating success factors, promoting for continuous improvement, and indicators of empowering data in the processes.

Table 1. A comparison between the discussed business process re-engineering frameworks.

\begin{tabular}{|c|c|c|c|c|c|c|c|}
\hline Framework & Mendling & Motwani & Al-Mashari and Zairi & Robert & Lowenthal & Cross et al. & TOGAF \\
\hline $\begin{array}{l}\text { Need analysis } \\
\text { and scoping }\end{array}$ & ○ & 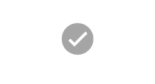 & 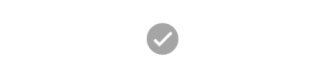 & 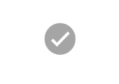 & ○ & 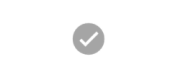 & ○ \\
\hline $\begin{array}{l}\text { Alignment with } \\
\text { business strategy }\end{array}$ & 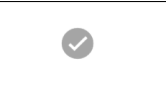 & ○ & 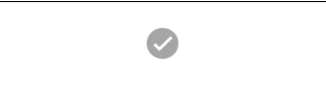 & & & 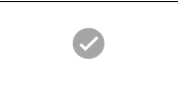 & 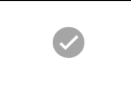 \\
\hline Benchmarking & 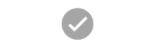 & 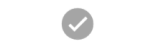 & ○ & & & ○ & 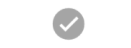 \\
\hline $\begin{array}{l}\text { Alternative modeling } \\
\text { and qualifying }\end{array}$ & 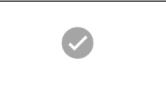 & ○ & ○ & $\odot$ & ○ & 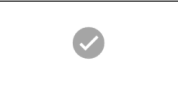 & 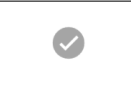 \\
\hline $\begin{array}{l}\text { Organisational } \\
\text { change impact }\end{array}$ & 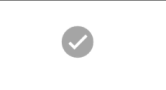 & 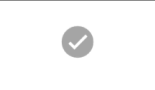 & 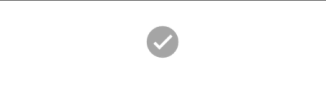 & 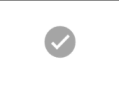 & & & 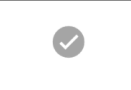 \\
\hline $\begin{array}{l}\text { Testing end-user } \\
\text { engagement }\end{array}$ & 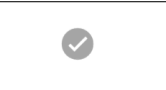 & 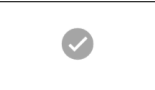 & ○ & ○ & & ○ & 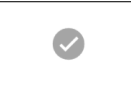 \\
\hline $\begin{array}{l}\text { Knowledge } \\
\text { management }\end{array}$ & 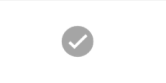 & 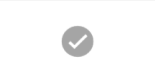 & & 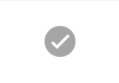 & & & 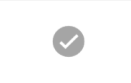 \\
\hline
\end{tabular}


Table 1. Cont.

\begin{tabular}{|c|c|c|c|c|c|c|c|}
\hline Framework & Mendling & Motwani & Al-Mashari and Zairi & Robert & Lowenthal & Cross et al. & TOGAF \\
\hline $\begin{array}{l}\text { Handling running } \\
\text { instances }\end{array}$ & 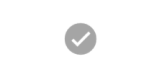 & & & 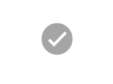 & & & 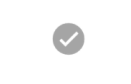 \\
\hline $\begin{array}{l}\text { Process performance } \\
\text { monitoring after } \\
\text { implementation }\end{array}$ & 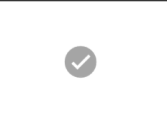 & 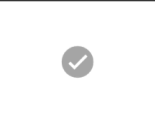 & & 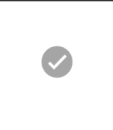 & & & 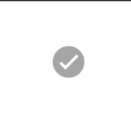 \\
\hline $\begin{array}{l}\text { Evaluation and setting } \\
\text { success factors }\end{array}$ & 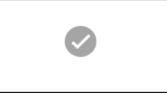 & 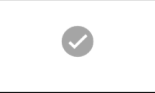 & 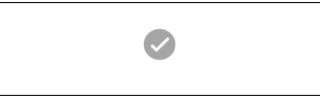 & 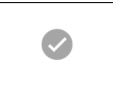 & 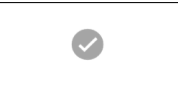 & 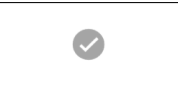 & 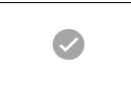 \\
\hline $\begin{array}{l}\text { Promoting for } \\
\text { continuous } \\
\text { improvements }\end{array}$ & 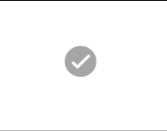 & & & ○ & & & 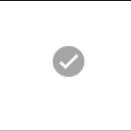 \\
\hline $\begin{array}{c}\text { Data use in } \\
\text { decision making }\end{array}$ & 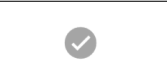 & ○ & 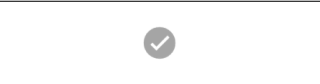 & 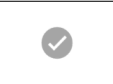 & 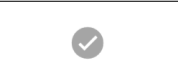 & 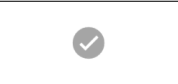 & 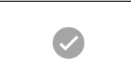 \\
\hline
\end{tabular}

The comparison above suggests considerable differences between the framework in terms of covered areas. Nevertheless, it does not necessarily reflect consistent framework performance in implementation projects.

Selecting a proper framework is one success factor where other success factors play an accumulative role in overall successful implementation. However, it indicates how critical it is to cover areas in the implementation projects to ensure a higher success rate. The comparison also indicated that data empowerment is present in all frameworks, a positive indicator for data mining and the machine-learning implementation model.

\subsection{Methodologies}

Business process re-engineering empowers well-proven methodology implementations. A methodology is an approach that uses governance frameworks, tools, and techniques to manage project progress for successful implementation [25]. Multiple proven methodologies are used for business processes improvement and re-engineering projects, such as Six Sigma, Lean Thinking, Lean Six Sigma, Total Quality Management, Kaizen, and Poka-Yoka [26].

In our review, we covered Lean, Six Sigma, Lean Six Sigma and Kaizen, as these are the most relevant methodologies to business process r-engineering projects:

- Lean methodology began with a manufacturing emphasis and was referred to as lean manufacturing for many years. Gradually, organisations learned that the same principles also applied to non-manufacturing processes [27]. John Y. Shook, and the Lean Global Network team [28], emphasise that Lean creates the most value for the customer while minimising resources, time, energy, and effort.

- The Six Sigma methodology was initially founded by Motorola, when facing extreme pressures from overseas competition, mainly Japan. Therefore, around 1987, Bill Smith and others began improvement projects that, in many ways, looked similar to TQM projects. Eventually, Mikel Harry and others helped Smith formulate this approach into an overall business initiative to protect Motorola's pager business. They named the initiative "Six Sigma". The name was based on the desire to reduce variation to the level that specification limits for in crucial process metrics, six standard deviations away from the target [27]. General Electric also played a very significant role in the development of Six Sigma as a methodology. General Electric CEO JackWelch loudly proclaimed that General Electric was jumping into the Six Sigma game in late 1995. Jack Welch defines Six Sigma as a quality program that, "when all is said and done", improves customer experience, lowers costs, and builds better leaders [27,29]. The Six Sigma methodology starts with identifying the need for an improvement initiative. However, when Motorola designed the initial version of the Six Sigma steps, it replaced the four phases of Measure, Analyse, Improve, and Control by 
General Electric. It did not have the Defining step. The Define phase was added before the Measure phase afterwards, in order to form the well-known Define, Measure, Analyse, Improve, and Control process (DMAIC) [27,29]. However, when a product or a service is under significant design change requirements or at an early stage of development, the five phases of Six Sigma change to Define, Measure, Analyse, Design, and Verify (DMADV). The change is to achieve a Six Sigma level right from the initial design, which is also called the Design For Six Sigma (DFSS) $[27,29]$. The Six Sigma methodology is a well-disciplined and structured approach used to enhance process performance and achieve high quality and low levels of variability [29].

- Lean Six-Sigma methodology eliminates waste and variation, following the DMAIC structure, as in the Six Sigma methodology, to achieve customer satisfaction regarding quality, delivery, and cost. In addition, it focuses on improving processes, satisfying customers, and achieving better financial results for the business [29].

- Kaizen, as a term, was coined by Masaaki Imai, as "KAI" means changes, and "ZEN" means improvement. The focus of the Kaizen methodology is to eliminate the activities that do not add value to the process [30].

Comparing these methodologies on their scope, objectives, technology empowerment, and data utilisation is in Table 2 below as a summary. The comparison suggests that all methodologies consider information technology a key enabler in deriving business process re-engineering projects. Additionally, the study indicates that all methodologies rely heavily on data to shape and derive change in the process design.

Table 2. A comparison between business process re-engineering frameworks.

\begin{tabular}{|c|c|c|c|c|}
\hline \multirow{2}{*}{ Characteristics } & \multicolumn{4}{|c|}{ Methodologies } \\
\hline & Lean & Six Sigma & Lean Six Sigma & Kaizen \\
\hline Scope & $\begin{array}{l}\text { Eliminating unwanted } \\
\text { activities }\end{array}$ & Reducing variance & $\begin{array}{l}\text { Waste elimination and } \\
\text { variation reduction }\end{array}$ & $\begin{array}{l}\text { Small and incremental } \\
\text { changes }\end{array}$ \\
\hline Objective & Reduction in workflow time & Process standardisation & $\begin{array}{l}\text { Process standardisation } \\
\text { and waste reduction }\end{array}$ & $\begin{array}{l}\text { Incremental continuous } \\
\text { improvements }\end{array}$ \\
\hline $\begin{array}{l}\text { Use of information } \\
\text { technology tools }\end{array}$ & Very high & Very high & Very high & Intermediate \\
\hline $\begin{array}{l}\text { Relying on data in } \\
\text { decisions making }\end{array}$ & High & High & High & High \\
\hline Change method & One time & Incremental & Continuing & Continuing incremental \\
\hline Associated risk levels & High & Moderate & Moderate & Moderate \\
\hline
\end{tabular}

The comparison suggests that all methodologies empower tools to generate and analyse data to improve or re-engineer the business process. Furthermore, the methodologies, especially those that promote incremental and continuous improvement approaches, empower data to analyse the performance and initiate another improvement cycle.

\subsection{Tools and Techniques}

Furthermore, the review indicates that both frameworks and methodologies employ tools and techniques throughout the process. In addition, the review found many tools and techniques used in business process re-engineering for different purposes. There are tools used for process discovery and process visualisation in order to have a helicopter view of the flow of the process from one activity to another and to view the roles and responsibilities in an overview (Table 3). Other tools for business process management include monitoring the business process's quality or analysing aspects of the process like process performance, reliability, and efficiency. 
Table 3. Tools used for business process re-engineering and optimisation.

\begin{tabular}{|c|c|c|c|c|}
\hline Type & & Tools and Techniqu & & References \\
\hline Process discovery and visualizing & $\begin{array}{ll}\text { - } & \text { Mylnvenio } \\
\text { - } & \text { ProM } \\
\text { - } & \text { Disco } \\
\text { - } & \text { Tree diagram }\end{array}$ & $\begin{array}{ll}- & \text { Affinity diagram } \\
- & \text { Arrow diagram } \\
- & \text { Matrix diagrams }\end{array}$ & $\begin{array}{ll}\text { - } & \text { Relations diagram } \\
\text { - } & \text { Process decision chart } \\
\text { Process mapping } \\
\text { flowcharts }\end{array}$ & {$[5,31-33]$} \\
\hline Quality management & $\begin{array}{ll}- & \text { PDCA } \\
- & \text { DMAIC } \\
- & \text { IDEA } \\
- & \text { Pareto chart }\end{array}$ & $\begin{array}{ll}\text { - } & \text { Control chart } \\
\text { - } & \text { 8Ds } \\
\text { - } & \text { Stratification }\end{array}$ & $\begin{array}{ll}\text { - } & \text { Histogram } \\
\text { - } & \text { Scatter diagram } \\
\text { - } & \text { Cause-and-effect } \\
& \text { diagram } \\
\text { - } & \text { Checklists or check sheet }\end{array}$ & {$[26,27,29,33-36]$} \\
\hline Analysis & $\begin{array}{l}\text { - The force fields. } \\
\text { - The 'measles' } \\
\text { chart } \\
\text { - } \quad \text { Benchmarking }\end{array}$ & $\begin{array}{ll}\text { - } & \text { Matrix analysis } \\
\text { - } & \text { Multi-vari charts }\end{array}$ & $\begin{array}{ll}\text { - } & \text { Total productive } \\
\text { maintenance } \\
\text { - } \\
\text { Cycle time management } \\
\text { (CTM) } \\
\text { - Kanban production } \\
\text { system }\end{array}$ & {$[26,29,36]$} \\
\hline
\end{tabular}

Nevertheless, an added value of using systemised tools and techniques, besides their impact on process improvement and re-engineering, is their practical use in generating, analysing, and visualising data throughout the process.

This review indicates that similar tools, as in Table 3 above, are implemented and used in business process re-engineering frameworks and methodologies. Additionally, the review indicates that using such tools is crucial to driving the implementation projects towards successful implementation.

\subsection{Success Factors}

Having a high success rate in implementation projects is the ultimate goal for any implementation team. However, business processes re-engineering projects were not always successful for multiple reasons, primarily associated with using best practices or industry standards in an industry field from other industrial experiences without adequately studying the unique requirements of the field [15]. Additionally, the failure rate is around $70 \%$ for business process re-engineering implementations, due to a lack of a proper framework or methodology appliance [15]. However, multiple factors play a vital role in the success and failure of a project. They can be looked at as indicators to predict the outcome of an implementation project and predict the percentage of the success chance.

Bhaskar [15] and Hashem [14] outlined the foundation of success and failure factors for a business process re-engineering implementation, which the researchers used to develop the following list of factors in Table 4 . The researchers added a category level to classify the factors into driver, strategic, or enabler categories. The driver factors derive the need for change and raise the flag in the organisation when the business process requires improvement. The strategic drivers direct and steer the project to implementation. The enabler factors are necessary to enable the successful implementation. The below listed factors may lead to project success or failure, as described in the table below (Table 4). 
Table 4. Implementation factors for success and failure.

\begin{tabular}{|c|c|c|c|}
\hline Category & Factor & Success & Failure \\
\hline Driver & $\begin{array}{c}\text { Alignment of business strategy for BPR } \\
\text { project and IT strategies }\end{array}$ & Aligned strategies & Lack of alignment and unclear strategy \\
\hline Driver & The focus of the change & Driven by customer needs & $\begin{array}{c}\text { Focuses on the process as a process and } \\
\text { drives the change on structural or pure } \\
\text { financial bases }\end{array}$ \\
\hline Strategic & Clarity on business needs & $\begin{array}{l}\text { Solid business case with a clear scope of } \\
\text { work }\end{array}$ & $\begin{array}{c}\text { Inadequate business case: unclear, } \\
\text { unreasonable, unrealistic scope, and } \\
\text { unjustifiable } \\
\text { expectations from the BPR project }\end{array}$ \\
\hline Strategic & BPR methodology and framework & $\begin{array}{l}\text { Selecting the best methodology and } \\
\text { framework for the project }\end{array}$ & Lack of innovation in process redesign \\
\hline Strategic & Data empowerment & $\begin{array}{l}\text { Data-driven change based on facts and } \\
\text { figures }\end{array}$ & Not having sufficient data \\
\hline Strategic & Change management strategy & $\begin{array}{l}\text { Having a solid change management } \\
\text { strategy, team, and change processes }\end{array}$ & Lack of change management \\
\hline Strategic & $\begin{array}{c}\text { Top management and critical } \\
\text { stakeholders engagement, leadership, } \\
\text { and motivation }\end{array}$ & $\begin{array}{l}\text { Highly engaged, supportive, and } \\
\text { committed }\end{array}$ & $\begin{array}{c}\text { Lacking support, poor commitment, and } \\
\text { poor leadership style }\end{array}$ \\
\hline Enabler & Operation team engagement & $\begin{array}{l}\text { Engaged and involved through the } \\
\text { project }\end{array}$ & Non or minimal engagement \\
\hline Enabler & Technology and digitalisation & $\begin{array}{l}\text { Adoptive and change dynamically } \\
\text { based on the need }\end{array}$ & $\begin{array}{l}\text { Lack of reliable advanced } \\
\text { technology }\end{array}$ \\
\hline Enabler & Training and education & Provided to all levels & Lack of training and education \\
\hline Enabler & Rewarding system & Fair & Unfair \\
\hline Enabler & Organisation culture & Flat and less bureaucratic Structure & Bureaucratic \\
\hline Enabler & Financial support & Adequate & \\
\hline Enabler & Working environment & $\begin{array}{l}\text { Collaborative and work towards shared } \\
\text { objectives and targets }\end{array}$ & Lack of collaborative work \\
\hline Enabler & Communication & $\begin{array}{l}\text { Effective communication with all } \\
\text { stakeholders }\end{array}$ & Ineffective communication \\
\hline Enabler & Business process re-engineering team & $\begin{array}{c}\text { Authorised, experienced, effective, and } \\
\text { skilled }\end{array}$ & $\begin{array}{l}\text { Insufficient authority that lacks } \\
\text { experience and skills }\end{array}$ \\
\hline
\end{tabular}

The table above suggests categorising technology and digitalisation as enabling factors in the implementation projects for success. The review found that engaging the right people at all levels is vital to successful implementation. Their involvement and the knowledge they contribute is a critical factor. Organisational culture and human factors are vital in implementing business process re-engineering towards success or failure implementation. Generally, all factors affect the business process re-engineering projects, yet the human factor is dominant [37]. Therefore, an ontology-based knowledge of Map Methodology (PROM) reduces the failure ratio, solves business process re-engineering project problems, and overcomes difficulties [38].

Furthermore, empowering data and data analytics in driving the decisions throughout the implementation impacts the success or failure of a project.

Having clear visibility of the project implementation success and failure factors, as in Table 4 above, makes it possible to predict the success or the failure of a business process re-engineering implementation through empowering the data and utilising data science and machine-learning concepts.

Therefore, supporting the decision-making process with a machine-learning algorithms is needed. Quantitatively relating the business process activities (Borgianni et al., 2015) improves the selection of the best fitting framework and methodology. 


\subsection{Data Mining and Machine Learning Use in Business Process Management}

Thus far, the review looks at available frameworks, methodologies, tools, and techniques used in the manual business process re-engineering process, as well as the success and failure factors. Therefore, the next step is to investigate machine learning and data mining utilisation. For that, the review surveyed $60+$ publications on subjects related to data mining and machine-learning applications for process management, process improvement, process re-engineering, process optimisation, process automation, process visualisation, process modelling, process planning, process discovery, and process behaviour.

The survey indicated a rising academic interest in studying and coupling process science, process mining, data mining, and machine learning (Figure 1). Over the years, this implies a considerable focus on process behaviour, process improvement, and business process management. However, the study indicates a shift in focus from understanding process behaviour and business process management in 2017 towards process improvement and optimisation in 2020, which is a natural evolution of the research focus from general to more specific research problems. In addition, machine learning growing capabilities have an optimistic outlook, and may be applied to more sophisticated challenges.

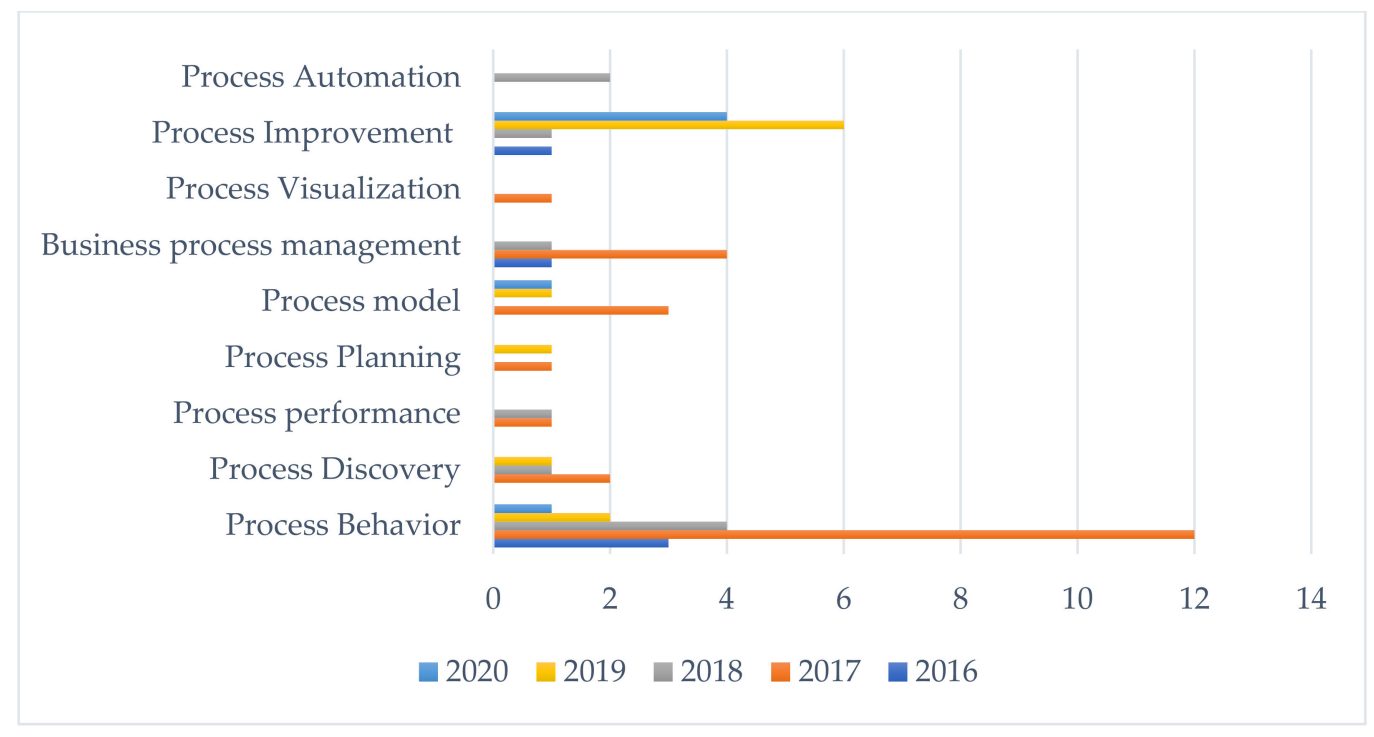

Figure 1. Level of focus on process mining subjects from the years 2016-2020.

Furthermore, the survey suggests that more papers were published in 2017 about process behaviour (Figure 2), indicating a trend driven by a group of researchers, such as Van Der Aalst and others.

Furthermore, the survey found that from the years 2017 until 2020, many process mining subjects were discussed and coupled with machine learning in different percentages.

With these findings, investigating literature on possible machine-learning implementations in business process re-engineering is the next step.

The study investigated previous implementations of machine learning and data mining for business process topics. The study found and reviewed 22 papers that qualified as per the selection criteria: an application of machine learning in the business process.

The findings in Table 5 indicate that machine learning was applied to process discovery, such as process event logs files, predicting process behaviour, improvement, and process optimisation. 


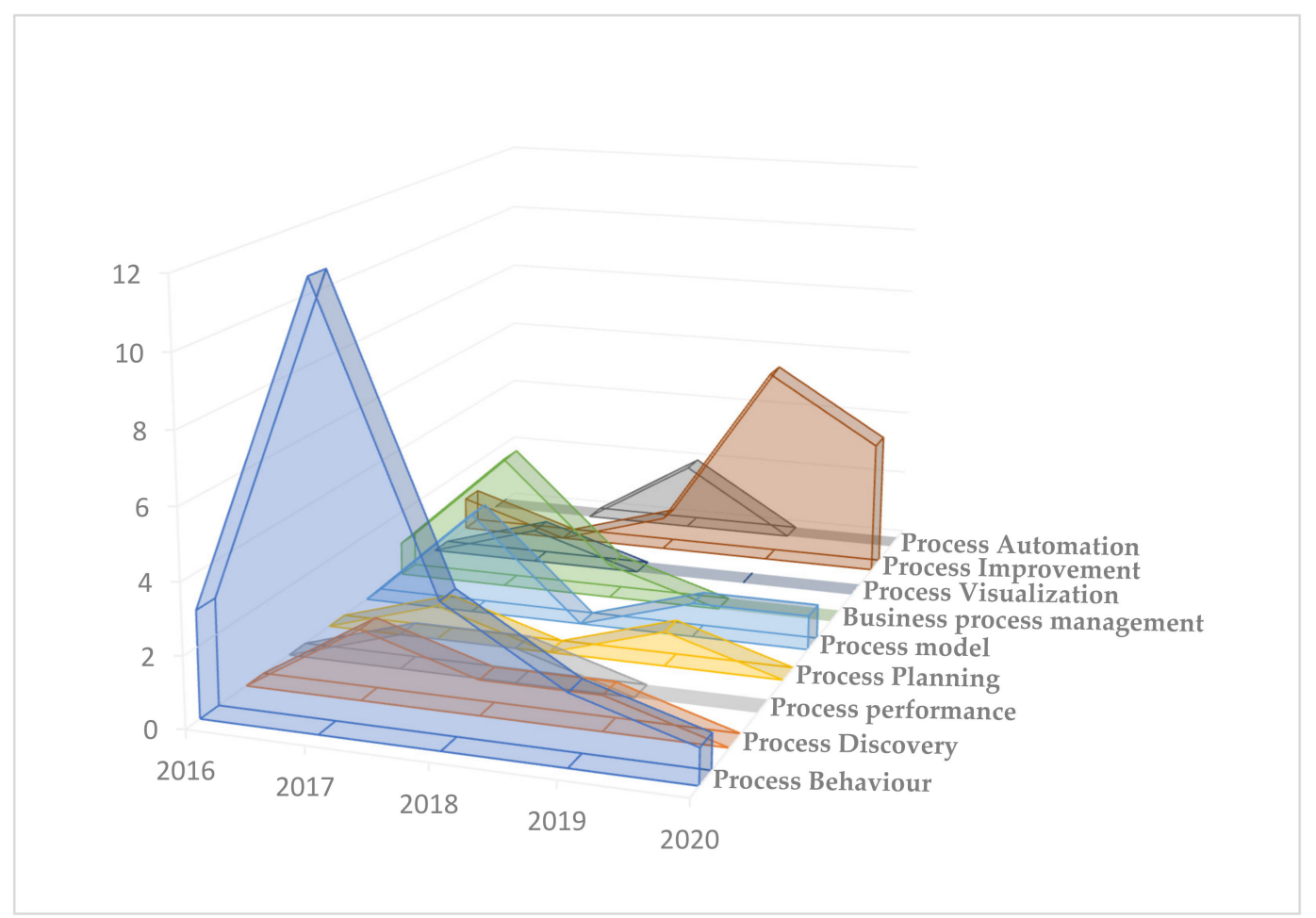

Figure 2. Level of coverage of process mining subjects from the years 2016-2020.

Table 5. Examples of machine-learning tasks and algorithms used for BPM.

\begin{tabular}{ccc}
\hline BPM Task & Algorithm(s) & References \\
\hline Process discovery & Decision tree & {$[32,39-43]$} \\
\hline \multirow{3}{*}{ Process behaviour prediction } & Deep Learning & {$[32,35,44-47]$} \\
\cline { 2 - 3 } & Support Vector Machine & {$[32]$} \\
\cline { 2 - 3 } & Hidden Markov Model & {$[32,48]$} \\
\cline { 2 - 3 } & Expectation-Maximisation & {$[39,48-51]$} \\
\hline Process improvement & Futural Language Processing & {$[52,53]$} \\
\hline & Decision tree & {$[33]$} \\
\hline Process optimisation & Mixed-Integer Linear Programs & {$[32,54]$} \\
\cline { 2 - 3 } & Support Vector Machine & {$[56]$} \\
\cline { 2 - 3 } & Greedy Algorithm & {$[57]$} \\
\hline
\end{tabular}

The review indicates that the decision tree algorithm used for process discovery applications is by Mannhardt, De Leoni [39], Kalenkova, Burattin [40], Leemans, Fahland [42], Verbeek and Mannhardt [43], Márquez-Chamorro, and Resinas [32]. The decision tree algorithm was appropriate for this problem type because it looked for hidden patterns in the provided process events and segmented process activities into flow scenarios. The most repeated pattern represents one option of the process flow scenarios with the possibility of having multiple exceptions to the original process flow.

Predicting the process behaviour was another application for machine-learning applications. The review indicates multiple algorithms used to solve it. For example, deep Learning neural networks were used by Márquez-Chamorro and Resinas [32], Zgodavova, Bober [35], Tax, Verenich [46], Chandramouleeswaran, Krzemien [47]. 
Furthermore, the study indicates that the number of implementations towards more complex problems like process improvement and optimisation are rare and not as popularly implemented as process behaviour prediction applications.

One exciting machine-learning application by Weichert et al. is optimising business processes for multiple industries, including machining, plastic manufacturing, and others. They applied machine-learning algorithms for defect detection, automatic visual inspection, and assembly fault detection. Weichert et al. claim an excellent level of use for machine learning in business process optimisation.

However, Weichert et al. indicated a scarcity in correlating the data, the amount of data, the machine-learning algorithms, and the respective production problems [34].

Khan et al. stressed initiatives to optimise the business process using machine learning and proposed a framework for automated re-engineering of business process modeling notation models by excluding inefficient activities [58]. Thus, Khan's work is tremendously essential in automating the process of business process re-engineering.

\section{Findings}

The literature review provided solid evidence that business process re-engineering is a very well established approach equipped with frameworks, methodologies, tools, and techniques. Additionally, the literature shows that the failure of a business process reengineering project is associated with many factors. One of them is having a knowledgeable implementation team, which is consequential to selecting the right tools and techniques. In addition to that, in 2020 and beyond, the COVID-19 pandemic affected the world and caused lockdowns that paralysed many industries. Because of the lockdowns, many organisations accelerated the implementation of digital transformation projects to enable their workers to continue working remotely. Relatively, digital transformation helped many organisations to rethink, redesign, simplify, and re-engineer their business processes [59]. This resulted in a massive demand for digitalisation and, consequently, business process re-engineering. As such, business process re-engineering projects became enormously expensive and time-consuming. On top of that, redesigning a business process requires extensive knowledge in the functional domain of the process. To explain, for example, an aviation process, requires aviation knowledge, and likewise, medical processes require medical knowledge.

The review aimed to investigate the level of use of machine learning in automating business process re-engineering. In addition, the review indicated increasing academic progress and interest in integrating machine learning and optimisation methods in order to improve processes. The review correlated that with the accelerated advances in the business environments derived by digitalisation and the resulting available data [36].

Nevertheless, the review indicates hardly any extreme use of the available process data in order to apply machine learning and improve the business process, confirming the findings of Weichert, D. et al. [36].

It also confirms that there is hardly any significant utilisation of machine-learning tools and techniques for automating re-engineering business processes. However, the literature review found humble attempts to automate business process re-engineering.

\section{Discussion}

The hypothesis of this study is that a machine-learning model trained to re-engineer a defined business process automatically is doable. So far, through the literature review, the study found opportunities to achieve that through the Lean Six Sigma and Kaizen methodologies.

Mimicking Lean Six Sigma concepts of reducing waste and variations in the business process is possible based on these findings. The researchers engaged and interviewed selected experienced business process re-engineering practitioners and Lean Six Sigma Black Belt holders from multiple industries, such as aviation, education, public service, automobile, and telecommunication. The main objective of these interviews was to identify 
the data they use and rely on when deciding on the re-engineering process. The output from these interviews is an initial set of data attributes and data sources. These can qualify as inputs for a machine-learning model inspired by the Lean Six Sigma way of thinking.

In addition, it was found that business processes in an organisation are generally categorised as business support processes or core business processes. The core business processes are entirely different from one industry to another, depending on the industry core business model and other factors. Contrarily, business support processes, such as human resources processes, finance and accounting processes, supply chain management processes, and information technology processes are usually standard across industries, with slight exceptions. However, because of legacy, bureaucracy, and other corporate cultural issues, the activities of the standard business process diverts; therefore, more activities are added. This becomes even worse when introducing exceptions to the business process (parallel processes).

In this sense, a machine-learning model could contribute to re-engineering a business process in an industry or an organisation, based on a learned pattern from another industry or organisation, for the same process or function.

While designing our model, we considered the anticipated process complexities, which vary from one process to another. As such, the proposed model looks at each activity in the process separately. The machine-learning model takes the featured data, as inputs, and examines them against a supervised machine-learning approach. The model then labels the input and recommends an action against each activity. After examining all process activities, the outcome is a re-engineered version of the original process. Below, Figure 3 gives a high-level illustration of how the proposed model works.
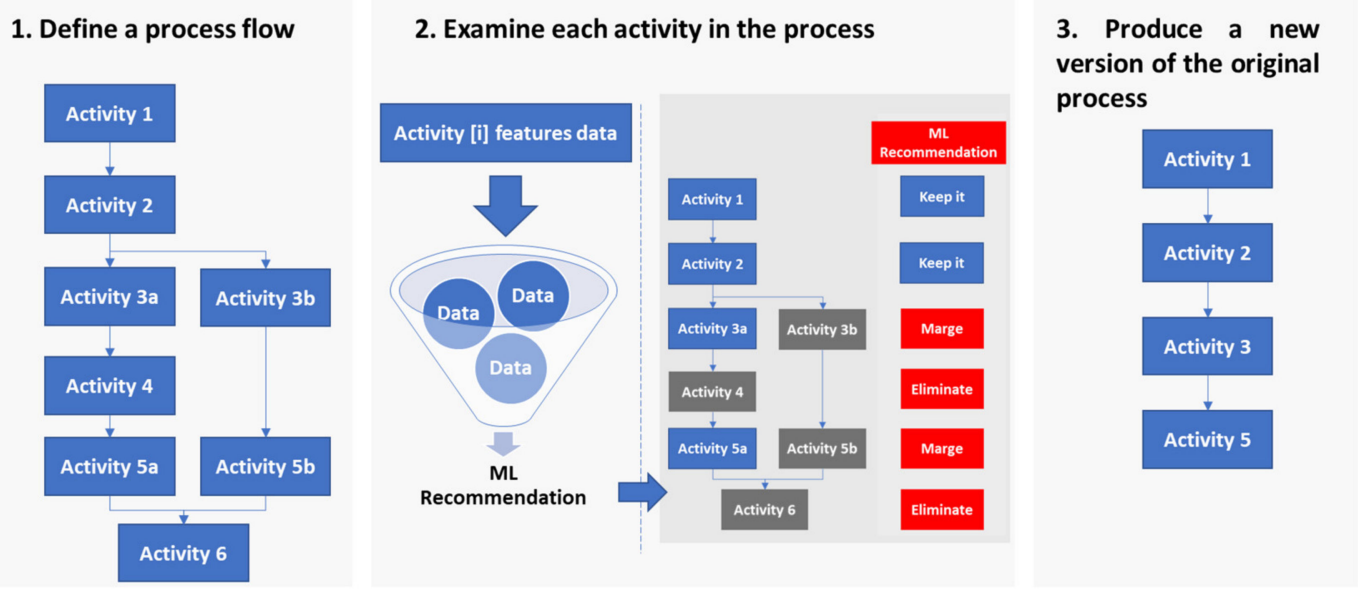

Figure 3. The proposed model of high-level illustration.

A machine-learning model requires data to learn from and test its accuracy in recommending and mapping labels to the feature records. However, there is a need to identify data attributes that can add value to the model in order to identify the required data sources and datasets.

Interviewing the Lean Six Sigma experts helps identify the following list of attributes (machine-learning features) as inputs to the machine-learning model:

- Process industry, e.g., aviation, telecommunication, manufacturing, and banking

- Process function, e.g., human resources, finance, supply chain, and production

- Process versions of history; the process version opens another dimension of the prediction model of the alternative process design.

- Activity performance against its KPIs: poor, good, and excellent. This attribute can be more accurate when the KPIs data are available.

- Activity operation cost value (acceptable? Yes or no). 
- Customer satisfaction level (from one to five); some companies implement customer satisfaction at each step.

- Does it make a bottleneck? (Yes or no).

- $\quad$ Are there enough resources to do the task? (Yes or no).

- Is it digitalised? (Yes or no).

- Can it be automated? (Yes or no).

- Is it an audit compliance check step? (Yes or no).

- Is it being performed by the same actor as the previous step in the process? (Yes or no).

- Activity value to the process (1-10)? If less than three, should it be eliminated?

- How relevant is the activity to the process objectives? (Relevant or irrelevant).

- Is it a service provided to customers step? (Yes or no).

- Is it an internal activity or does it require external input? Internal is meant in the sense of the organisation, specifically, the function department.

- $\quad$ Stakeholder level. (VIP, owner, consumer, employee, and system).

- Is it business-to-business or business-to-customer?

Depending on the organisation's documentation policy, digitalisation, and automation, these data attributes can be available in the organisation. In modernised organisations, a digital business process management platform would have all the necessary data and more. Such platforms document all of the process lifecycles, from the initial process modelling, process versions updates, process activities, process audit logs, and process execution data, to the retiring of the business process. Some organisations even link their social media accounts to the business process management platform. Social media helps in improving the level of service and solving disputes with clients.

In general, we have identified the below-listed possible sources for the data. These could be functional modules in business process management platforms, stand-alone separated systems, or data repositories.

The data sources are:

- Process modelling repository

- Process execution data

- Process events logging database

- Process performance KPIs

- Process owner feedback

- Experienced process engineer decision

Except for the last item in the list above, the data can be on one platform, as highlighted above. Moreover, through the literature review, it was found that there are applications of machine learning that discover the process flow in event logs. Other implementations are to predict process behaviour, which can help learn the process performance.

Undeniably, there will be challenges with the data. However, the challenges are situational, i.e., each implementation initiative will have different challenges to overcome, and as the general guidelines are defined, this will help.

In order to bring the data sources closer to the identified attributes, Figure 4 below mapped the identified data attributes to possible data sources. 

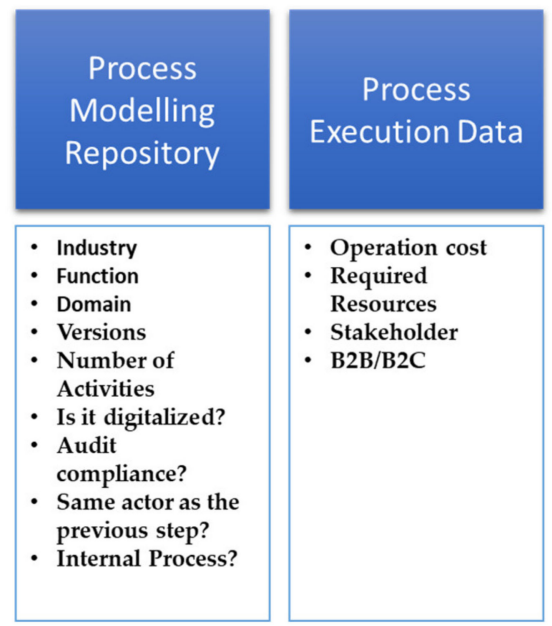
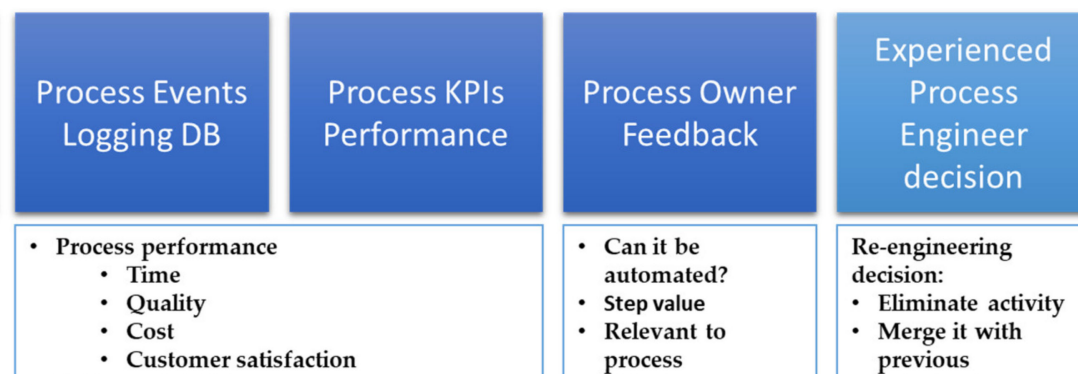

- Process performance

- Time

- Quality

- Cost

- Customer satisfaction

- Bottleneck?[Y/N]

- Can it be
automated?
- Step value
- Relevant to
process
objectives.
- Interacting with
customers?

\begin{tabular}{l}
\hline Re-engineering \\
decision: \\
- Eliminate activity \\
- Merge it with \\
previous \\
- Split it to two steps \\
\end{tabular}

Figure 4. Possible data sources mapped to data attributes.

Below, Figure 5 is a prototype illustration of the machine-learning model in action. In this example, the machine recommends keeping the activity step 1 and justifies it because of the step value.

\section{Activity 1}
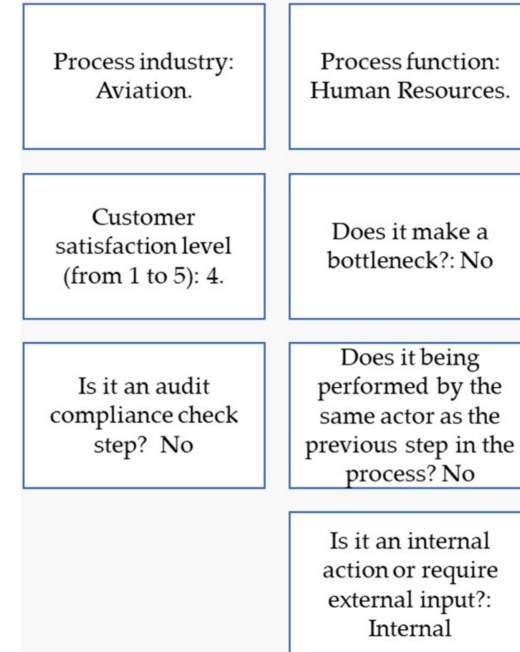
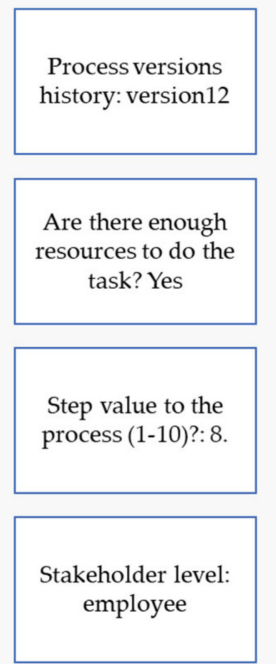

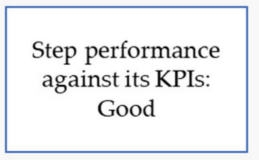

Step operation cost value is acceptable: Yes

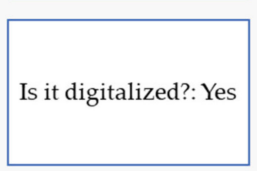

$$
\begin{aligned}
& \text { How relevant is the } \\
& \text { action to the process } \\
& \text { objectives? Relevant }
\end{aligned}
$$
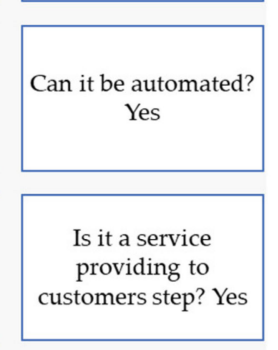

Is it a business-tobusiness or businessto-customer? business-to-customer

ML Recommendation Keep this Activity, as it's value is high

Figure 5. Illustration of the machine-learning model in action.

The identified list of input attributes is evolving and can be expanded and challenged with more attributes. As expected, adding more to the list will make the ML output more accurate because some of the new features could be better than the existing ones. Therefore, its evolving nature should improve its performance. Below, Table 6 is a projected sample data of records of attributes with supervised and predicted label results. If we added the industry and function attributes to them, they would impact the predicted result in one way or another. Relatively, identifying new attributes would give us better options in selecting better input for better output. 
Table 6. Sample data of ML model attributes.

\begin{tabular}{|c|c|c|c|c|c|c|c|c|c|}
\hline Step ID. & Performance & Is Bottleneck & Enough Resources & Automated & Audit Step & Same Actor as the Previous or the Next Step & Step Value & Relevant & Prediction Result \\
\hline 1 & Poor & No & Yes & No & No & No & 6 & Relevant & Keep \\
\hline 2 & Good & Yes & No & No & No & No & 5 & Relevant & Keep \\
\hline 3 & Poor & Yes & Yes & No & Yes & Yes & 2 & Relevant & Merge \\
\hline 4 & Excellent & No & Yes & Yes & No & No & 8 & Relevant & Eliminate \\
\hline
\end{tabular}

Another important aspect is the amount of available data. Considering the size of an organisation, the number of processes they have, and their complexity, determines the available amount of data. In a middle-sized organisation, the number of active business processes can reach up to 200 (the number is a projected number based on experience, as learned from the interviews, and there is no reference to support it yet to match to reality) processes between human resources, finance, accounting, supply chain management, and information technology departments. The organisation can have more processes, depending on its core operation.

The illustration in Figure 5 and the sample data in Table 6 suggest having three output results for the supervised machine-learning algorithm: keep the activity, merge with previous, or eliminate the activity. However, through examining more data, the model would mature and would recommend more accurate and reasonable results like automating and merging activities, eliminating activities from the process, splitting an activity into two, or other recommendation classifications. The sample data and the ML model are at an early stage of development, requiring experimental work as future work for the researchers.

The outcome from the model then needs to be verified. Hence, since business process re-engineering relies heavily on industry and functional knowledge, the verification will require engaging experts on the subject matter. The expected outcome of implementing the proposed machine learning would be a leaner process if the process were not at its leaner shape. In addition, such a tool can be a practice of continuous improvement for evolution and providing better insights.

\section{Conclusions}

In conclusion, this study indicates that business process re-engineering is a scientifically matured field. The study found that business process re-engineering is equipped with many solid frameworks, methodologies, tools, and techniques; this is an eye-catching finding because of the amount of generated and analysed data through the re-engineering process. The data are enormously helpful for analysing the process performance, scientifically deciding the need to re-engineer a business process, and finding a re-engineered business process for the evolving business requirements.

The review also found few efforts to utilise machine learning for business process re-engineering. This confirms that academia could contribute more to automating business process re-engineering with artificial intelligence and machine learning.

This study proposes a novel solution to automate the business process re-engineering, and is inspired by relevant Lean Six Sigma methodology principles, derived from the core concept of eliminating waste and variants.

In future work, the researchers intend to experiment and qualify the proposed solution in multiple case studies. In addition, we are aiming to develop a platform publicly available for experts to exploit and challenge.

Author Contributions: Conceptualization, Y.A.-A., A.A.-H., M.A.-B. and R.H.; methodology, Y.A.-A. and A.A.-H.; validation, A.A.-H., M.A.-B. and R.H.; formal analysis, Y.A.-A.; investigation, Y.A.-A.; resources, Y.A.-A.; data curation, Y.A.-A.; writing-original draft preparation, Y.A.-A.; writingreview and editing, Y.A.-A.; visualization, Y.A.-A.; supervision, A.A.-H., M.A.-B. and R.H.; project administration, Y.A.-A. All authors have read and agreed to the published version of the manuscript.

Funding: This research received no external funding. 
Institutional Review Board Statement: Not applicable.

Informed Consent Statement: Not applicable.

Data Availability Statement: The data supporting the reported results in the present study will be available on request from the corresponding author or the first author.

Conflicts of Interest: The author declares no conflict of interest.

\section{References}

1. Sujová, A.; Simanová, L.; Marcineková, K. Reengineering of production processes and its impact on the financial situation and business performance of the company. Eng. Manag. Prod. Serv. 2019, 11, 106-116. [CrossRef]

2. Tsakalidis, G.; Vergidis, K. Towards a Comprehensive Business Process Optimization Framework. In Proceedings of the 2017 IEEE 19th Conference on Business Informatics (CBI), Thessaloniki, Greece, 24-27 July 2017; IEEE: Piscataway, NJ, USA, 2017; Volume 1, pp. 129-134. [CrossRef]

3. Harmon, P. Business Process Change: A Business Process Management Guide for Managers and Process Professionals; Morgan Kaufmann Publishers: Burlington, MA, USA, 2019.

4. Brocke, J.V.; Mendling, J. Frameworks for business process management: A taxonomy for business process management cases. In Business Process Management Cases; Springer: New York, NY, USA, 2017; pp. 1-17. [CrossRef]

5. Van der Aalst, W.M. Process Mining: Data Science in Action; Springer: New York, NY, USA, 2016.

6. Burattin, A. Process Mining Techniques in Business Environments; Springer: New York, NY, USA, 2015.

7. Karagiannis, D.; Woitsch, R. Knowledge engineering in business process management. In Handbook on Business Process Management 2; Springer: New York, NY, USA, 2014; pp. 623-648. [CrossRef]

8. Hitpass, B.; Astudillo, H. Industry 4.0 Challenges for Business Process Management and Electronic-Commerce. J. Theor. Appl. Electron. Commer. Res. 2019, 14. [CrossRef]

9. Fakorede, O. SNACH A New Framework to Support Business Process Improvement. Ph.D. Thesis, Bournemouth University, Poole, UK, 2020.

10. Cadavid, J.P.U.; Lamouri, S.; Grabot, B.; Fortin, A. Machine Learning in Production Planning and Control: A Review of Empirical Literature. IFAC PapersOnLine 2019, 52, 385-390. [CrossRef]

11. Eliakina, N. Digital Transformation: Identifying areas for process optimization in Credit Management department, Case Corporation X. Ph.D. Thesis, Vaasaan Ammattikorkeakoulu University of Applied Sciences, Vaasa, Finland, 2018.

12. Gupta, S.; Modgil, S.; Gunasekaran, A. Big data in lean six sigma: A review and further research directions. Int. J. Prod. Res. 2019, 58, 947-969. [CrossRef]

13. Bako, Y.; Banmeke, M. The impact of business process re-engineering on organizational performance (A study of commercial banks and micro-finance banks in Ilaro). J. Manag. Technol. 2019, 5, 1-14.

14. Hashem, G. Organizational enablers of business process reengineering implementation. Int. J. Product. Perform. Manag. 2019, 69, 321-343. [CrossRef]

15. Bhaskar, H.L. Business process reengineering framework and methodology: A critical study. Int. J. Serv. Op. Manage. 2018, 29, 527-556.

16. Saltz, J.S.; Dewar, N. Data science ethical considerations: A systematic literature review and proposed project framework. EthicInf. Technol. 2019, 21, 197-208. [CrossRef]

17. Cirne, R.; Melquiades, C.; Leite, R.; Leijden, E.; Maciel, M.A.A.; de Lima Neto, F.B. Data Mining for Process Modeling: A Clustered Process Discovery Approach. In Proceedings of the 15th Conference on Computer Science and Information Systems (FedCSIS), Sofia, Bulgaria, 6-9 September 2020.

18. Freiesleben, J.; Keim, J.; Grutsch, M. Machine learning and Design of Experiments: Alternative approaches or complementary methodologies for quality improvement? Qual. Reliab. Eng. Int. 2020, 36, 1837-1848. [CrossRef]

19. Watton, R. Project Management Framework: A Structure for All Organisations; PMF Management Solutions: Logan, Australia, 2015.

20. Mendling, J.; Baesens, B.; Bernstein, A.; Fellmann, M. Challenges of smart business process management: An introduction to the special issue. Decis. Support. Syst. 2017, 100,1-5. [CrossRef]

21. Chountalas, P.T.; Lagodimos, A.G. Paradigms in business process management specifications: A critical overview. Bus. Process. Manag. J. 2018, 25, 1040-1069. [CrossRef]

22. Binci, D.; Belisari, S.; Appolloni, A. BPM and change management: An ambidextrous perspective. Bus. Process Manag. J. 2019, 26. [CrossRef]

23. Bhasin, S.; Dhami, S. Business Process Reengineering-The Role of Human Resource Function: A Comprehensive Review of Literature. Int. J. Bus. Manag. Res. 2018, 8036, 1-18.

24. Harrison, R. Togaf (r) 9 Foundation Study Guide; Van Haren: Hertogenbosch, The Netherlands, 2018.

25. Joslin, R. Project Management Methodologies, Governance and Success: Insight from Traditional and Transformative Research; CRC Press: Boca Raton, FL, USA, 2019.

26. Zaini, Z.; Saad, A. Business Process Reengineering as the Current Best Methodology for Improving the Business Process. J. ICT Educ. 2019, 6, 66-85. [CrossRef] 
27. Antony, J.; Snee, R.; Hoerl, R. Lean Six Sigma: Yesterday, today and tomorrow. Int. J. Qual. Reliabil. Manag. 2017, $34,1073-1093$. [CrossRef]

28. Shook, J.Y. Lean Global Network. What is Lean Thinking and Practice? 2018. Available online: http://leanglobal.org/what-islean/ (accessed on 7 March 2021).

29. Salah, S.; Rahim, A. The integration of six sigma and lean. In An Integrated Company-Wide Management System; Springer: New York, NY, USA, 2019; pp. 49-93. [CrossRef]

30. Goyal, A.; Agrawal, R.; Chokhani, R.K.; Saha, C. Waste reduction through Kaizen approach: A case study of a company in India. Waste Manag. Res. 2018, 37, 102-107. [CrossRef]

31. Es-Soufi, W.; Yahia, E.; Roucoules, L. On the Use of Process Mining and Machine Learning to Support Decision Making in Systems Design. In Proceedings of the IFIP 13th International Conference on Product Lifecycle Management, Colombia, SC, USA, 11-13 July 2016; Springer: New York, NY, USA, 2016; pp. 56-66. [CrossRef]

32. Marquez-Chamorro, A.E.; Resinas, M.; Ruiz-Cortes, A. Predictive Monitoring of Business Processes: A Survey. IEEE Trans. Serv. Comput. 2017, 11, 962-977. [CrossRef]

33. Bergner, M.; Johannsen, F.F. Supporting business process improvement with natural language processing: A model-based approach. Informatik 2016, 2016, 717-730.

34. Buer, S.-V.; Fragapane, G.I.; Strandhagen, J.O. The Data-Driven Process Improvement Cycle: Using Digitalization for Continuous Improvement. IFAC Papers OnLine 2018, 51, 1035-1040. [CrossRef]

35. Zgodavova, K.; Bober, P.; Majstorovic, V.; Monkova, K.; Santos, G.; Juhaszova, D. Innovative Methods for Small Mixed Batches Production System Improvement: The Case of a Bakery Machine Manufacturer. Sustainability 2020, 12, 6266. [CrossRef]

36. Weichert, D.; Link, P.; Stoll, A.; Rüping, S.; Ihlenfeldt, S.; Wrobel, S. A review of machine learning for the optimization of production processes. Int. J. Adv. Manuf. Technol. 2019, 104, 1889-1902. [CrossRef]

37. Omidi, A.; Khoshtinat, B. Factors Affecting the Implementation of Business Process Reengineering: Taking into Account the Moderating Role of Organizational Culture (Case Study: Iran Air). Procedia Econ. Finance 2016, 36, 425-432. [CrossRef]

38. AbdEllatif, M.; Farhan, M.S.; Shehata, N.S. Overcoming business process reengineering obstacles using ontology-based knowledge map methodology. Futur. Comput. Informatics J. 2018, 3, 7-28. [CrossRef]

39. Mannhardt, F.; de Leoni, M.; Reijers, H.A.; van der Aalst, W.M.P. Decision mining revisited-discovering overlapping rules. In Proceedings of the International Conference on Advanced Information Systems Engineering, Yanuca Island Coral Coast Fiji Islands, Fiji, 28 June-2 July 2016; Springer: New York, NY, USA, 2016.

40. Kalenkova, A.; Burattin, A.; de Leoni, M.; van der Aalst, W.; Sperduti, A. Discovering high-level BPMN process models from event data. Bus. Process. Manag. J. 2018, 25, 995-1019. [CrossRef]

41. Broucke, S.K.V.; de Weerdt, J. Fodina: A robust and flexible heuristic process discovery technique. Decis. Support. Syst. 2017, 100, 109-118. [CrossRef]

42. Leemans, S.J.J.; Fahland, D.; van der Aalst, W.M.P. Scalable process discovery and conformance checking. Softw. Syst. Model. 2016, 17, 599-631. [CrossRef]

43. Verbeek, H.; Mannhardt, F. The Dr Furby Classifier Submission to the Process Discovery Contest@ BPM 2016; BPM Center Report BPM-16-08; BPM Center: San Pedro, CR, USA, 2016.

44. Evermann, J.; Rehse, J.-R.; Fettke, P. Predicting process behaviour using deep learning. Decis. Support. Syst. 2017, 100, 129-140. [CrossRef]

45. Neu, D.A.; Lahann, J.; Fettke, P. A systematic literature review on state-of-the-art deep learning methods for process prediction. Artif. Intell. Rev. 2021. [CrossRef]

46. Tax, N.; Verenich, I.; la Rosa, M.; Dumas, M. Predictive business process monitoring with LSTM neural networks. In Proceedings of the International Conference on Advanced Information Systems Engineering, Essen, Germany, 12-16 June 2017; Springer: New York, NY, USA, 2017.

47. Chandramouleeswaran, K.R.; Krzemien, D.; Burns, K.; Tran, H.T. Machine Learning Prediction of Airport Delays in the US Air Transportation Network. In Proceedings of the Aviation Technology, Integration, and Operations Conference, Atlanta, GA, USA, 25-29 June 2018. [CrossRef]

48. Breuker, D.; Hitfox Group; Matzner, M.; Delfmann, P.; Becker, J.; University of Muenster; University of Koblenz-Landau. Comprehensible Predictive Models for Business Processes. MIS Q. 2016, 40, 1009-1034. [CrossRef]

49. Sammaknejad, N.; Zhao, Y.; Huang, B. A review of the expectation maximization algorithm in data-driven process identification. J. Process. Control. 2019, 73, 123-136. [CrossRef]

50. Mannhardt, F.; de Leoni, M.; Reijers, H.A.; van der Aalst, W.; Toussaint, P.J. From Low-Level Events to Activities-A PatternBased Approach. In Proceedings of the International Conference on Business Process Management, Rio de Janeiro, Brazil, 18-22 September 2016; Springer: New York, NY, USA, 2016; pp. 125-141. [CrossRef]

51. Lu, X.; Fahland, D.; Andrews, R.; Suriadi, S.; Wynn, M.T.; ter Hofstede, A.H.M.; der Aalst, W. Semi-Supervised Log Pattern Detection and Exploration Using Event Concurrence and Contextual Information (Extended Version); BPM Center report BPM-17-01. In Proceedings of the OTM Confederated International Conferences "On the Move to Meaningful Internet Systems", Rhodes, Greece, 23-27 October 2017.

52. Arunkumar, C.; Ramakrishnan, S. Attribute selection using fuzzy roughset based customized similarity measure for lung cancer microarray gene expression data. Futur. Comput. Informatics J. 2018, 3, 131-142. [CrossRef] 
53. Song, Y.-G.; Cao, Q.-L.; Zhang, C. Towards a new approach to predict business performance using machine learning. Cogn. Syst. Res. 2018, 52, 1004-1012. [CrossRef]

54. Rosalina, R. A Comparison of Machine Learning Algorithms in Manufacturing Production Process. Communication Inf. Technol. J. 2019, 13, 17-23. [CrossRef]

55. Kratsch, W.; Manderscheid, J.; Reißner, D.; Röglinger, M. Data-driven Process Prioritization in Process Networks. Decis. Support. Syst. 2017, 100, 27-40. [CrossRef]

56. Denkena, B.; Dittrich, M.-A.; Uhlich, F. Self-optimizing Cutting Process Using Learning Process Models. Procedia Technol. 2016, 26, 221-226. [CrossRef]

57. Meilicke, C.; Leopold, H.; Kuss, E.; Stuckenschmidt, H.; Reijers, H.A. Overcoming individual process model matcher weaknesses using ensemble matching. Decis. Support. Syst. 2017, 100, 15-26. [CrossRef]

58. Khan, R.; Azam, F.; Maqbool, B.; Waseem Anwar, M. A Framework for Automated Reengineering of BPMN Models by Excluding Inefficient Activities. In Proceedings of the 9th International Conference on Software and Computer Applications, Langkawi, Malaysia, 18-21 February 2020.

59. Soto-Acosta, P. COVID-19 Pandemic: Shifting Digital Transformation to a High-Speed Gear. Inf. Syst. Manag. 2020, 37, 260-266. [CrossRef] 